\title{
Expression of Vascular Endothelial Growth Factor in the Gastric Mucosa of Patients with Portal Hypertensive Gastropathy
}

\author{
Naglaa El-Toukhy ${ }^{1}$ and Naglaa Al-Husseini ${ }^{2}$ \\ ${ }^{1}$ Department of Hepatology, Gastroenterology and Infectious Diseases, Faculty of Medicine, \\ Benha University, Egypt \\ ${ }^{2}$ Department of Biochemistry, Faculty of Medicine, Benha University, Egypt
}

Corresponding Author Naglaa El-Toukhy

Mobile: 01224720998

\section{E mail:}

naglaaeltoukhy@ yahoo.com

Key words: VEGF, Gastric mucosa, Portal Hypertensive Gastropathy
Background and study aim: Portal hypertensive gastropathy (PHG) is a common finding in patients with cirrhosis and portal hypertension that occurs in between $7 \%$ and $98 \%$ of cases. High levels of vascular endothelial growth factor (VEGF) in mesentery suggested their contribution in portal hypertension secondary to liver cirrhosis. VEGF participates in regulation of angiogenesis in gastric wall in portal hypertension. The aim was to evaluate the serum concentration of VEGF and gastric mucosal expression of VEGF and its possible association with PHG.

Patients and Methods: Serum levels and gastric mucosal expression of VEGF were measured in fifty seven patients with liver cirrhosis and portal hypertensive gastropathy as well as eleven patients with liver cirrhosis without portal hypertensive gastropathy and another twenty one persons served as control group. They were clinically assessed and laboratory investigations were done including liver biochemical profile, and viral markers. Severity of liver disease was assessed by Child-Pugh, model for end stage liver disease (MELD) and updated (uMELD) scores. The presence of PHG was diagnosed by esophagogastroduodenoscopy.

Results: Serum VEGF increased in patients with liver cirrhosis compared to healthy control. But there was no significant difference between patients with PHG and patients without PHG as regard to serum VEGF.VEGF expression in the gastric mucosa was highly significant in patients with PHG than patients without PHG and control group. Serum VEGF has no correlation with severity of liver disease or PHG grade.

Conclusion: VEGF was highly expressed in gastric mucosa rather than elevation of serum VEGF in patients with PHG.

\section{INTRODUCTION}

Portal hypertensive gastropathy (PHG) is a common finding in patients with cirrhosis and portal hypertension [1] and it is endoscopically characterized by a mosaic-like or snake skin pattern of the gastric mucosa, mainly in the body and fundus of the stomach and more rarely in the gastric antrum. These gastric mucosal lesions represent another frequent cause of upper gastrointestinal bleeding, even though esophagogastric varices remain the major source of bleeding in patients with portal hypertension [2]. PHG observed during endoscopy in patients with cirrhosis are very common, occurring in between $7 \%$ and $98 \%$ of cases according to different series [3].
Vascular endothelial growth factor (VEGF) is a secreted, $46 \mathrm{kDa}$ dimeric protein, active as direct and specific mitogen for vascular endothelial cells thus a well-known mediator of angiogenesis in physiological and pathological conditions [4]. High levels of VEGF in mesentery suggested its contribution in portal hypertension secondary to liver cirrhosis. ${ }^{5}$ High serum VEGF in late stage may reflect its prognostic value in liver cirrhosis [5]. VEGF participates in regulation of angiogenesis in gastric wall in portal hypertension [6]. Very few studies have been recently published about this issue. So, the aim of this study was to evaluate the serum concentration of VEGF and gastric mucosal expression of VEGF and their possible association with PHG in patients with cirrhosis. 


\section{PATIENTS AND METHODS}

\section{Patients :}

The current study was carried out on 68 patients with liver cirrhosis divided into two groups according to presence or absence of PHG attended or admitted to Hepatology, Gastroenterology and Infectious Diseases Department, Benha University Hospital, within the period between October 2014 and March2015, after approval by the scientific committee of Benha Faculty of Medicine. Another twenty-one persons served as control group.

Patients with cirrhosis were diagnosed by clinical manifestations, laboratory investigations and ultrasonography. Patients were classified according to presence or absence of portal hypertensive gastropathy which was diagnosed by upper gastrointestinal endoscopy.

Patients with congestive heart failure, renal failure, lung disease, malignancy, hepatic encephalopathy, gastrointestinal bleeding was excluded from this work at the time of study .

\section{Methods :}

All patients were subjected to full history taking thorough clinical examination and routine laboratory tests including liver biochemical profile as serum bilirubin (total, direct), serum albumin, prothrombin time, international normalized ratio and serum creatinine, viral markers: HCVAb (Hepatitis C virus antibody) and $\mathrm{HBsAg}(\mathrm{Hepatitis} \mathrm{B}$ virus surface antigen).Each patient was assigned a score and a grade reflecting the severity of liver affection according to:

- The numerical system of Child Turcotte Pugh (CTP) [7].

- MELD score (Model for End Stage Liver Disease) [8].

- uMELD score ( Updated Model for End Stage Liver Disease).[9].

VEGF was measured in serum of all subjects: using Human Vascular Endothelial Growth Factor ELISA Kit. Expression of VEGF in gastric mucosa was measured in all cases $[\mathbf{1 0 , 1 1 ]}$.

Pelvi-abdominal Ultrasonography was done using (LOGIC LG) with a convex probe (3.75 MHZ) for evaluation of liver (size, echopattern and portal vein, presence of focal lesion), evaluation of spleen (size and echopattern) and the presence of ascites.

Esophagogastroduodendoscopy was done using disinfected upper gastrointestinal video scope (OLYMPUS model) after good preparation of the patient. Complete evaluation of the esophagus, stomach and the duodenum down to the second part of the duodenum. Esophageal varices were classified as small or large [12].

- small esophageal varices were defined as: Varices that flatten with insufflation or minimally protrude into the esophageal lumen.

- While large esophageal varices were defined as: Varices that protrude into the esophageal lumen and touch each other (presence of confluence), or that fill at least $50 \%$ of the esophageal lumen.

The grading (I-IV) classification:

- grades I and II were reclassified as small and

- grades III and IV were reclassified as large for this study.

PHG were reported according to Modified grading system proposed by the Baveno III meeting (Baveno, Italy (2000) on portal hypertension [13]

- PHG is mild when a pink mosaic-like mucosal pattern with no red signs or black-brown spots is present.

- PHG is severe when the mosaic-like mucosal pattern is red and superimposed by any red sign (red point lesions and/or cherry-red spots) or black-brown spots.

Gastric mucosal biopsies were taken for studying the expression of VEGF.

\section{Statistical Analysis :}

Statistical package (SPSS, version 10.0) was used for data management. Descriptive statistics was presented as mean \pm standard deviations for continuous variables, number and percentage for categorical variables (frequency distribution). Unpaired Student t-test (two sided) was used to test the significance of difference between the mean value of studied groups and chi -square test was used for comparison of categorical variables. Pearson correlation test was used to identify the correlation between VEGF and different clinicopathological variables. The significance level was set at $\mathrm{p}<0.05$.

\section{RESULTS}

\section{Characteristics of the studied patients :}

Sixty eight patients with liver cirrhosis were included in this study. The cases were divided into two groups according to presence or absence of PHG, cases with PHG were fifty seven while the other eleven cases had no PHG. The mean age was 53.5 \pm 9.1 in patients with PHG compared 
to $55.9 \pm 10.6$ in patients without PHG. There was no statistically significant difference between groups as regards to the age and gender but PHG tends to be more common in males than females (males were 35 cases and females were 22 cases).

HCV infection was found in $98.2 \%$ of patients. Most of patients presented at Child B grade, and had a higher MELD and uMELD scores. By ultrasonography; spleen size and Portal vein diameter were higher in cirrhotics with PHG than in cirrhotic without PHG cases. Otherwise, other ultasonographic parameters did not distinguish between the two groups (Table 1).

Regarding endoscopy, fifty seven cases had endoscopically based portal hypertensive gastropathy $(83.8 \%)$ and eleven had no portal hypertensive gastropathy (16.2\%). large varices were detected in $(61.4 \%)$ of patients with PHG and small varices in $(31.6 \%)$ of patients (Table 2$)$.

\section{Serum VEGF in the studied groups :}

Concerning serum VEGF value, it was significantly increased in cirrhotic patients with PHG as it ranges between (34-234.1) $\mathrm{pg} / \mathrm{ml}$ with mean (65.3) $\mathrm{pg} / \mathrm{ml}$ and also in cirrhotic patients without PHG as it ranges between (38.8-99.5) $\mathrm{pg} / \mathrm{ml}$ with mean (62.7) $\mathrm{pg} / \mathrm{ml}$ compared to control group as it ranges between (24.4-37.5) $\mathrm{pg} / \mathrm{ml}$ with mean (28.3) $\mathrm{pg} / \mathrm{ml}$, but there was no statistically significant difference between cirrhotic patients with PHG and cirrhotic patients without PHG (Table 3).

\section{Expression of VEGF in gastric mucosa in studied groups :}

VEGF expression in gastric mucosa was highly significantly expressed in patients with liver cirrhosis with PHG than cirrhotic patients without PHG and control group (Table 4 and Figure 1,2).

\section{VEGF and severity of liver disease :}

There was no significant correlation between VEGF and severity of liver disease (Child, MELD and UMELD), varices grade, number of varices or PHG grade (Table 5).

Table (1) : Demographic features of the studied patient groups

\begin{tabular}{|c|c|c|c|}
\hline Characteristics & $\begin{array}{c}\text { Patients with PHG } \\
(\mathrm{n}=57)\end{array}$ & $\begin{array}{c}\text { Patients without PHG } \\
(\mathrm{n}=11)\end{array}$ & P. value \\
\hline $\begin{array}{l}\text { Age (years) } \\
\text { Range } \\
\text { Mean }+ \text { SD }\end{array}$ & $\begin{array}{c}32-72 \\
53.5 \pm 9.1\end{array}$ & $\begin{array}{c}35-70 \\
55.9 \pm 10.6\end{array}$ & 0.455 \\
\hline $\begin{array}{l}\text { Gender } \\
\text { Male } \\
\text { Female }\end{array}$ & $\begin{array}{l}35(61.4 \%) \\
22(38.6 \%)\end{array}$ & $\begin{array}{l}5(45.5 \%) \\
6(54.5 \%)\end{array}$ & 0.256 \\
\hline $\begin{array}{l}\text { Occupation } \\
\text { Farmer } \\
\text { Non- farmer } \\
\end{array}$ & $\begin{array}{c}10(17.5 \%) \\
26(65 \%) \\
\end{array}$ & $\begin{array}{l}1(9.1 \%) \\
16(80 \%) \\
\end{array}$ & 0.34 \\
\hline $\begin{array}{l}\text { Etiology } \\
\text { Smoking } \\
\text { Shistosomiasis } \\
\text { HCV } \\
\text { HBV }\end{array}$ & $\begin{array}{c}19(33.3 \%) \\
20(35.1 \%) \\
56(98.2 \%) \\
1(1.8 \%)\end{array}$ & $\begin{array}{c}4(36.4 \%) \\
0(0 \%) \\
11(100 \%) \\
1(9.1 \%)\end{array}$ & $\begin{array}{c}0.55 \\
0.015^{*} \\
0.83 \\
0.18\end{array}$ \\
\hline $\begin{array}{c}\text { Child- Pugh score } \\
\text { Child A } \\
\text { Child B } \\
\text { Child C }\end{array}$ & $\begin{array}{l}12(21.05 \%) \\
33(57.89 \%) \\
12(21.05 \%)\end{array}$ & $\begin{array}{l}3(27.72 \%) \\
4(36.36 \%) \\
4(36.36 \%)\end{array}$ & $\begin{array}{l}0.64 \\
0.66 \\
0.55\end{array}$ \\
\hline $\begin{array}{l}\text { MELD Score } \\
\text { Mean }+ \text { SD }\end{array}$ & $21+8.2$ & $14.2+4.6$ & $0.02 *$ \\
\hline $\begin{array}{l}\text { uMELD Score } \\
\text { Mean } \pm \text { SD }\end{array}$ & $4.4+0.79$ & $3.2 \pm 0.4$ & $0.000 *$ \\
\hline $\begin{array}{l}\text { Ultrasound } \\
\text { Spleen size } \\
\text { PV }(\mathrm{cm})) \\
\text { Ascites } \\
\end{array}$ & $\begin{array}{c}13.8 \pm 4.2 \\
1.9 \pm 0.6 \\
31(5 \overline{6} .4 \%)\end{array}$ & $\begin{array}{l}10.3 \pm 8.1 \\
1.4 \pm 0.2 \\
8(72.7 \%) \\
\end{array}$ & $\begin{array}{c}0.02 * \\
0.01 * \\
0.14\end{array}$ \\
\hline
\end{tabular}

PHG, portal hypertensive gastropathy; SD, Standard deviation; HCV, hepatitis c virus; HBV, hepatitis B virus; MELD, Model for end stage liver disease; uMELD , updated MELD; PV, portal vein; *, Significant. 
Table (2) : Endoscopic features of the studied patients

\begin{tabular}{|l|c|c|c|c|c|}
\hline \multirow{2}{*}{ Variables } & \multicolumn{2}{|c|}{ Group I PHG } & \multicolumn{2}{c|}{ Group II Non PHG } & \multirow{2}{*}{ P-value } \\
\cline { 2 - 5 } & N & \% & N & \% & \\
\hline Varices & 53 & 93 & 9 & 81.8 & 0.24 \\
Small varices & 18 & 31.6 & 5 & 45.5 & 0.24 \\
Large varices & 35 & 61.4 & 4 & 36.4 & 0.26 \\
Gastric varices & 9 & 16.1 & 1 & 9.1 & 0.48 \\
PHG grade & & & & & \\
Mild & 26 & 45.6 & --- & --- & -- \\
Severe & 31 & 54.4 & --- & -- & -- \\
\hline
\end{tabular}

PHG, portal hypertensive gastropathy

Table (3) : Values of VEGF among the studied groups

\begin{tabular}{|l|c|c|c|c|c|c|c|}
\hline \multirow{3}{*}{ Variable } & \multicolumn{2}{|c|}{$\begin{array}{c}\text { Group I PHG } \\
\text { N=57 }\end{array}$} & \multicolumn{2}{|c|}{$\begin{array}{c}\text { Group II Non PHG } \\
\text { N=11 }\end{array}$} & \multicolumn{2}{|c|}{$\begin{array}{c}\text { Group III Control } \\
\text { N=21 }\end{array}$} & \multirow{2}{*}{$\begin{array}{c}\text { P- } \\
\text { value }\end{array}$} \\
\cline { 2 - 8 } & Range & Mean \pm SD & Range & Mean \pm SD & Range & Mean \pm SD & \\
\hline $\begin{array}{l}\text { VEGF } \\
(\mathrm{pg} / \mathrm{ml})\end{array}$ & $34-234.1$ & $65.3 \pm 31.1$ & $38.8-99.5$ & $62.7 \pm 17.9$ & $24.4-37.5$ & $28.3 \pm 3.9$ & $0.000^{*}$ \\
\hline
\end{tabular}

VEGF, vascular endothelial growth factor; PHG, portal hypertensive gastropathy; *, Significant; SD, Standard deviation.

Table (4) : Expression of VEGF by folds in gastric mucosa among the studied groups

\begin{tabular}{|c|c|c|c|c|}
\hline Variable & $\begin{array}{c}\text { Group I } \\
\text { PHG }\end{array}$ & $\begin{array}{c}\text { Group II Non } \\
\text { PHG }\end{array}$ & $\begin{array}{c}\text { Group III } \\
\text { Control }\end{array}$ & P - value \\
\hline VEGF (folds) & 31.12 & 6.06 & 1.0 & I,II $: 0.002^{*}$ \\
& & & & I,III: $0.000^{*}$ \\
& & & & II,III: $0.009^{*}$ \\
\hline
\end{tabular}

VEGF, vascular endothelial growth factor; PHG, portal hypertensive gastropathy; *, Significant. 


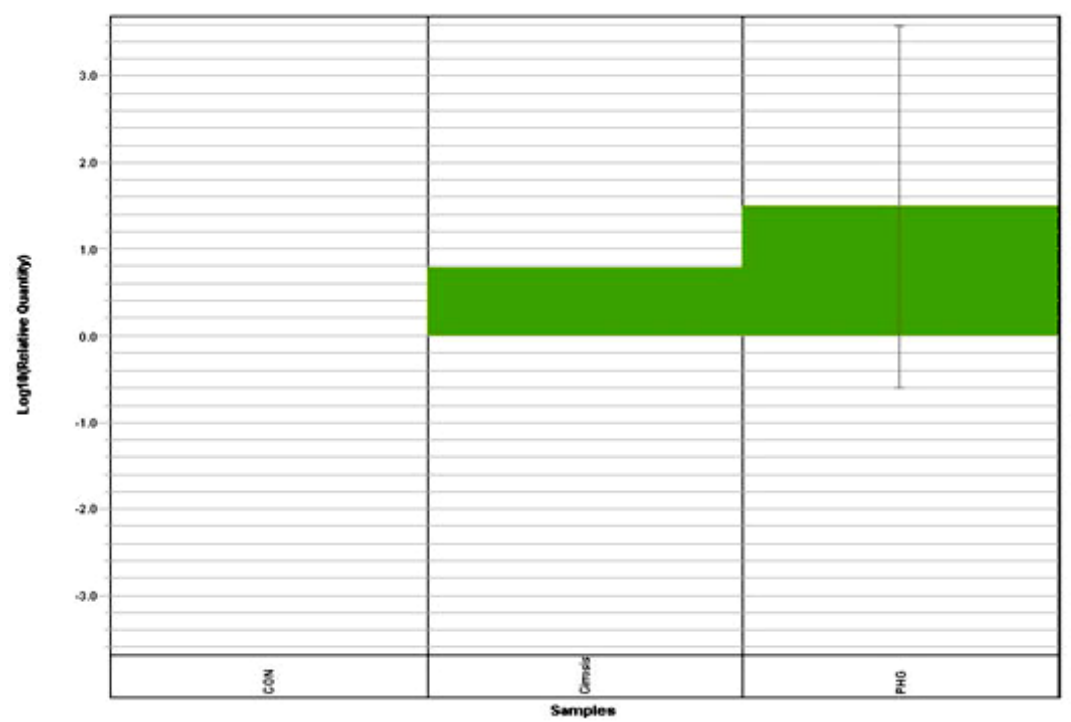

Figure (1) : Expression levels of VEGF mRNA for Both PHG and non PHG Sample. Expression levels of VEGF mRNA in both PHG and non PHG samples are indicated by green bars. This color also indicates the samples in RQ. Because control samples are used as calibrators, the expression levels are set to one. But because the expression levels were blotted as $\log \neg 10$ values (and the $\log 10$ of 1 is 0 ), the expression level of the control samples appear as 0 in the graph. Because the relative quantities of the VEGF mRNA are normalized against the relative quantities of the GAPDH (endogenous control), the expression level of the endogenous control is 0 ; there are no bars for GAPDH.

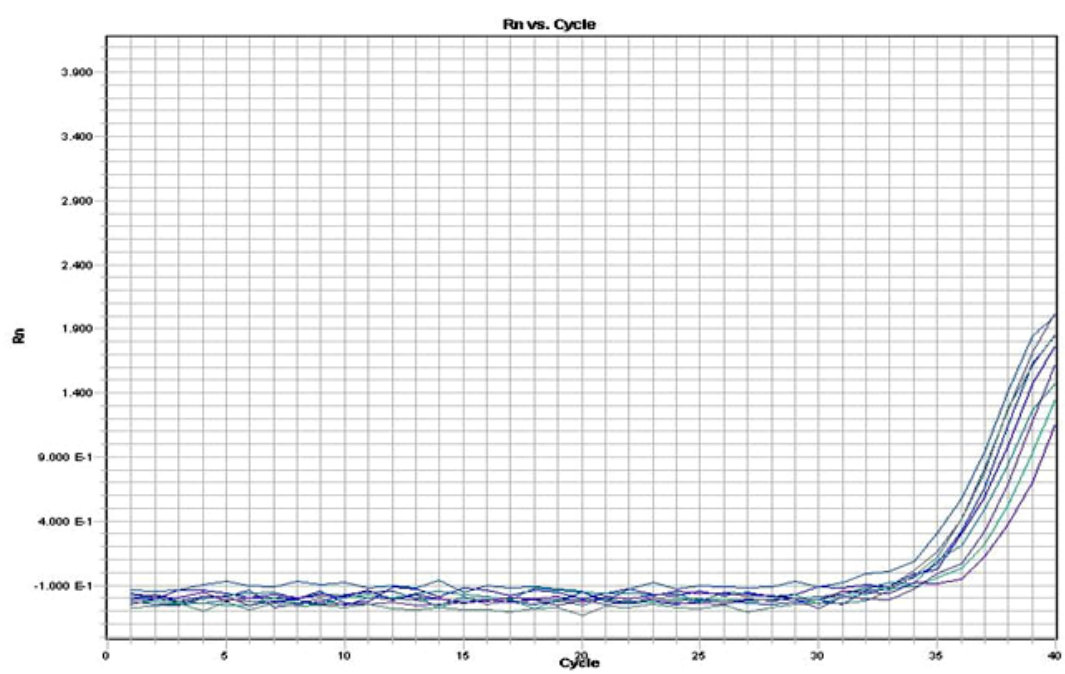

Figure (2) : Amplification plot curves for all detectors in the studied groups (Curves by ABI 7900 Real Time)

Table (5) : Correlation between VEGF and different parameters in PHG cases

\begin{tabular}{|l|c|c|}
\hline \multicolumn{1}{|c|}{ VEGF } & Pearson correlation & P-value \\
\hline Child Score & -0.18 & 0.34 \\
MELD & -0.14 & 0.5 \\
uMELD & -0.13 & 0.53 \\
Varices grade & -0.04 & 0.69 \\
Number of varices & -0.1 & 0.42 \\
PHG garde & -0.03 & 0.78 \\
\hline
\end{tabular}

VEGF, vascular endothelial growth factor; PHG, portal hypertensive gastropathy; MELD, Model for end stage liver disease; UMELD , updated MELD. 


\section{DISCUSSION}

Portal hypertensive gastropathy ( $\mathrm{PHG}$ ) is a unique endoscopic finding in cirrhosis and portal hypertension is the main cause for the development of PHG [1].

PHG is clinically important because it may cause acute (and even) massive or insidious, blood loss. The diagnosis of PHG is (only) made endoscopically; which is often characterized by an abnormality of the gastric mucosa described as a mosaic-like pattern resembling 'snake-skin', with or without red spots [14].

In the present study, PHG was observed in $(83.8 \%)$ of patients, PHG was mild in $(45.6 \%)$ of patients and severe in $(54.4 \%)$ of patients, these results were near to the results of Kim et al. who observed PHG in (90\%) of patients, PHG was mild in $(25.4 \%)$ and severe in $(64.7 \%)$ of patients [15].

In this study, endoscopy revealed that PHG cases were associated with varices in $(93 \%)$ of patients, (35) of them $(61.4 \%)$ were with large varices and (18) of them $(31.6 \%)$ of patients were with small varices; these results were in agreement with the results of Kim et al. who documented that PHG was associated with esophageal varices grade and the prevalence of PHG was higher in patients with large esophageal varices than in those with small sized varices [15]. This may results from a more severe portal hypertension in patients with both severe PHG and large esophageal varices. Moreover, in our study, endoscopy revealed that there was no significant difference between the two groups as regard to presence of gastric varices, these results agreed with the results of Kim et al. who stated that there was no correlation between gastric varices and PHG [15].

Concerning VEGF serum values, our results showed that it was significantly increased in cirrhotic patients with PHG as it ranges between (34-234.1) $\mathrm{pg} / \mathrm{ml}$ with mean (65.3) $\mathrm{pg} / \mathrm{ml}$ and also in cirrhotic patients without PHG as it ranges between $(38.8-99.5) \mathrm{pg} / \mathrm{ml}$ with mean (62.7) $\mathrm{pg} / \mathrm{ml}$ compared to control group which ranges between ( 24.4-37.5) pg/ml with mean ( $28.3) \mathrm{pg} / \mathrm{ml}$, these results agreed with the results of Jaroszewicz et al. who observed also that VEGF value was significantly increased in liver cirrhosis with mean (153.1) $\mathrm{pg} / \mathrm{ml}$ compared to healthy individuals $(46.8) \mathrm{pg} / \mathrm{ml}$ [16], our results also agreed with Abdelmoaty et al. who documented that VEGF value was significantly increased in liver cirrhosis with mean(106.1) $\mathrm{pg} / \mathrm{ml}$ compared to healthy individuals (41.5) $\mathrm{pg} / \mathrm{ml}$ [5].These results indicate possible association between VEGF signaling pathway and enhanced angiogenesis during liver cirrhosis [16].

As regard to serum VEGF level, the results showed that there is no significant difference between patients with PHG and patients without PHG, this may be due to the fact that the level of portal VEGF is significantly higher than that of systemic VEGF [17], while in the present study we measured the level of VEGF in systemic circulation only and not in portal circulation as recorded by Snowdon et al. [18].

Expression of VEGF in gastric mucosa was highly significant in patients with liver cirrhosis without PHG (6.06 folds to control) and cirrhotic patients with PHG (31.12 folds to control) than control group, these results may be explained by Abdelmoaty et al who stated that VEGF might be involved in cirrhosis associated angiogenesis [5].

The previous results agreed with the results of Pan et al. who showed a significantly elevated expression of VEGF in the gastric walls during the development of portal hypertension, the expression was mainly located in the basal layer of the gastric mucosa, suggesting that VEGF plays a certain role in the vascular changes of the gastric wall in portal hypertensive gastropathy [6]. These results agreed also with the results of Colle et al. who observed in patients and in animal models that there is an increased expression of VEGF in portal hypertensive gastric mucosa and can be involved in the development of portal hypertensive gastropathy [19]. Previous studies found in vivo increased angiogenesis in the mesenteric microvasculature of an experimental model of portal hypertension rats with cirrhosis, also showed increased expression of VEGF in the mesentery of these rats, which was significantly higher compared with the control groups [5]. Gjeorgjievski and Cappel proposed that gastric mucosal hypoxia and elevation of VEGF might accelerate mucosal angiogenesis and increase blood flow [20].

Concerning the VEGF and severity of liver disease assessed by Child-Pugh score, MELD score and UMELD score, our results showed that there is no significant correlation between VEGF and these scores which was in agreement with Assy et al. who documented that circulating VEGF level in patients with liver cirrhosis could not serve as an indicator of the progression of 
chronic liver disease but rather, they may reflect increased portal hypertension or decreased hepatic regenerative activity or the combination of both [21].

Concerning the VEGF and varices grade, our results showed that there is no significant correlation between them, which is similar to the results of Makhlouf et al. [22].

\section{CONCLUSION}

In conclusion, the serum VEGF increase in patients with liver cirrhosis compared to healthy control. According to the expression VEGF in gastric mucosa, it was highly significant in patients with PHG than patients without PHG and control group. The serum VEGF didn't increase in patients with advanced stages of liver cirrhosis, which is reflected by Child-Pugh score, MELD score and uMELD score or with PHG grade as well.

\section{Funding: None}

\section{Conflicts of interest: None}

Ethical Approval: A written informed consent was taken from all included patients, and the study was approved by the Ethical Committee of our institution.

\section{REFERENCES}

1 Perini RF, Camara PR, Ferraz JG. Pathogenesis of portal hypertensive gastropathy: translating basic research into clinical practice. Nat. Clin. Pract. Gastroenterol.Hepatol.2009;6:150-158.

2 Rafailidis S, Demertzidis C, Ballas K, Alatsakis M, Symeonidis N, Pavlidis T et al. Effect of early propranolol administration on portal hypertensive gastropathy in cirrhotic rats.World J. Gastroenterol. 2009; 15: 4284-4289.

3 SeckinY, Harputluoglu MM, Batcioglu K, Batcioglu K, Karincaoglu M, Yildirim B et al. Gastric Tissue Oxidative Changes in Portal Hypertension and Cirrhosis. Dig. Dis. Sci. 2007; 52:1154-1158

4 Carmeliet P, Jain RK. Angiogenesis in cancer and other diseases.Nature 2000;407:249-57

5 Abdelmoaty MA, Bogdady AM, Attia MM, Zaky NA. Circulating vascular endothelial growth factor and nitric oxide in patients with liver cirrhosis: A possible association with liver function impairment.
Indian Journal of Clinical Biochemistry 2009; 23: 398-403.

6 Pan W-D, LiuY, Lin N, Fan Y, Qian X, Wang K, Zhang F. The Expression of PEDF and VEGF in the Gastric Wall of Prehepatic Portal Hypertensive Rats.Hepato-Gastroenterology2011; 58:2152-2155

7 Pugh RN, Murray-Lyon IM, Dawson JL, Pietroni $\mathrm{MC}$, Williams $\mathrm{R}$.Transection of the oesophagus for bleeding esophageal varicies.Br $J$ Surg. 1973;60:646-49.

8 Kamath PS, Wiesner RH, Malinchoc M, Kremers W, Therneau TM, Kosberg CL et al. "A model to predict survival in patients with end-stage liver disease". Hepatology 2001;33: 464-70.

9 Sharma P, Shaubel DE, Sima CS, Merion RM, Lok ASF. Re-weighting the model for end-stage liver disease score components.Gastroenterology 2008; 135:1575-1581.

10 Livak KJ, Schmittgen TD. Analysis of relative gene expression data using real times quantitative PCR and the 2-delta delta CT Method. METHODS 2001;25: 402-408.

11 Al Husseini NF, Odaa MM, Mohamed MA, Abd El Wahab WB, Hasan AA. Expression of adiponectin receptors in human placenta and itspossible implication in gestational diabetes. Am. J. Biochem. Biotechnol. 2010; 6: 136-140.

12 Sarwar S, Khan AA, Alam A, Butt AK, Shafqat F, Malik K et al. Effect of Band Ligation on Portal Hypertensive GastropathyandDevelopment of Fundal Varices.J .Ayub Med. Coll. Abbottabad-Pakistan 2006; 18: 32-35.

13 De Franchis R. Updating consensus in portal hypertension: report of the Baveno III Consensus Workshop on definitions, method-logy and therapeutic strategies in portal hypertension. J.Hepatol.2000; 33:846-852.

14 Cubillas R, Rockey DC. Portal hypertensive gastropathy:A review.Liver international2010;30: 1094-1102

15 Kim MY, Choi H, Baik SK, Yea CJ, Won CS, Byun JW et al. Portal Hypertensive Gastropathy: Correlation with Portal Hypertension and Prognosis in Cirrhosis. Dig. Dis. Sci. 2010;55:3561-3567

16 Jaroszewicz M, Januszkiewicz M, Flisiak, R, Rogalska M, Kalinowska A, Wierzbicka I. Circulating vascular endothelial growth factor and its soluble Receptors in patients with liver cirrhosis: Possible association with hepatic function impairment. Cytokine 2008; 44: 14-17

17 Tarantino G, Citro V, Conca P, Riccio A, Tarantino $\mathrm{M}$, Capone D et al. What are the implications of the spontaneous spleno-renal shunts in liver cirrhosis?. BMC Gastroenterol.2009;9: 89. 
18 Snowdon VK, Guha N, Fallowfield JA. Noninvasive Evaluation of Portal Hypertension: Emerging Tools and Techniques. International Journal of Hepatology.2012; Article ID 691089, 1-7.

19 Colle I, Geerts AM, Steenkiste CV, Van Vlierberghe H. Hemodynamic Changes in Splanchnic Blood Vessels in Portal Hypertension. The Anatomical Record 2008; 291: 699-713

20 Gjeorgjievski M, Cappel MS. Portal hypertensive gastropathy: A systemic review of the pathophysiology, clinical presentation, natural history and therapy. World Journal of Hepatology2016; 8:231-262.

21 Assy N, Paizi M, Gaitini D, Baruch Y, and Spira G. Clinical implication of VEGF serum levels in cirrhotic patients with or without portal hypertension .WJG.1999; 5:296-300

22 Makhlouf MM, Awad A, Zakharia MM, Fouad M, Saleh WA. Vascular endothelial growth factor level in chronic liver diseases. J.Egypt. Soc. Parasitol.2002; 32:907-21. 